Review

\title{
Potential and existing mechanisms of enteric methane production in ruminants
}

\author{
Junyi Qiao ${ }^{1,2}$, Zhiliang $\operatorname{Tan}^{1 *}$, Min Wang ${ }^{1}$
}

${ }^{1}$ The Chinese Academy of Sciences/Institute of Subtropical Agriculture - Key Lab. for Agro-Ecological Processes in Subtropical Region/South-Central Experimental Station of Animal Nutrition and Feed Science in Ministry of Agriculture 410125 - Hunan, PR - China.

2University of the Chinese Academy of Sciences - 100000 Beijing, PR - China.

${ }^{*}$ Corresponding author <zltan@isa.ac.cn>

Edited by: Concepta Margaret McManus Pimentel

\begin{abstract}
Enteric methane $\left(\mathrm{CH}_{4}\right)$ emissions in ruminants have attracted considerable attention due to their impact on greenhouse gases and the contribution of agricultural practices to global warming. Over the last two decades, a number of approaches have been adopted to mitigate $\mathrm{CH}_{4}$ emissions. However, the mechanisms of methanogenesis have still not been fully defined. According to the genome sequences of $M$. ruminantium in the rumen and of M. AbM4 in the abomasum, the pathways of carbon dioxide $\left(\mathrm{CO}_{2}\right)$ reduction and formate oxidation to $\mathrm{CH}_{4}$ have now been authenticated in ruminants. Furthermore, in the light of species or genera description of methanogens, the precursors of methanogenesis discovered in the rumen and research advances in related subjects, pathways of acetate dissimilation via Methanosarcina and Methanosaeta as well as metabolism of methanol to $\mathrm{CH}_{4}$ might be present in the rumen, although neither process has yet been experimentally demonstrated in the rumen. Herein the research advances in methanogenesic mechanisms including existing and potential mechanisms are reviewed in detail. In addition, further research efforts to understand the methanogenesis mechanism should focus on isolation and identification of more specific methanogens, and their genome sequences. Such increased knowledge will provide benefits in terms of improved dietary energy utilization and a reduced contribution of enteric $\mathrm{CH}_{4}$ emissions to total global greenhouse gas emissions from the ruminant production system.

Keywords: methanogenesis, carbon dioxide, formate, acetate, methanol
\end{abstract}

methanogenesis in order to ensure a specific intervention in methanogens that maintains the normal digestive functions of other microbes in the rumen. This review will comprehensively describe the species or genera of methanogens and all the pathways of methanogenesis in ruminants.

first century, primarily due to the increas greenhouse gases in the atmosphere. With over 21 times more heat per molecule than carbon dioxide $\left(\mathrm{CO}_{2}\right)$, methane $\left(\mathrm{CH}_{4}\right)$ is a particularly potent greenhouse gas and accounts for $16 \%$ of total global greenhouse gas emissions. The $\mathrm{CH}_{4}$ formation is a microbial-driven process, mainly dominated by methanogens, which are members of the Archaea domain and inhabit certain anaerobic environments, such as freshwater sediments abundant in organic matter, swamps and waterlogged soils, sewage treatment plants as well as the rumen of ruminants (Woese et al., 1978). Nowadays, ruminants can produce globally more than 80 million tons of $\mathrm{CH}_{4}$, which annually, accounts for $28 \%$ of anthropomorphic emissions, and has drawn attention to the contribution of animal agriculture to global warming (Beauchemin et al., 2008). In ruminants, enteric $\mathrm{CH}_{4}$ emissions not only contribute to global climate warming, but also account for $2 \sim 12$ $\%$ of the ingested energy. In particular, for high-producing lactating animals, at least $6 \%$ of gross energy intake is lost by way of $\mathrm{CH}_{4}$ emissions. Therefore, mitigating $\mathrm{CH}_{4}$ emissions in ruminants will not only assist in the achievement of international commitments under the Kyoto Protocol but also in the improvement of energy utilization efficiency and the performance of the host animal. Any mitigation option should be undertaken on the basis of a clear understanding of the mechanism of

\section{Methanogens in the rumen}

Methanogens belong to the phylum Euryarchaeota of the domain Archaea, and are divided into the following five orders, namely Methanosarcinales, Methanomicrobiales, Methanobacteriales, Methanococcales and Methanopyrales. In the rumen, methanogens are a large and diverse group of Archaea. Usually, the populations of methanogens range from $10^{7}$ to $10^{9} \mathrm{~g}^{-1}$ of rumen contents in concentrate-fed ruminants and are up to $10^{9}$ to $10^{10} \mathrm{~g}^{-1}$ of rumen contents in pasture-fed ruminants (Attwood et al., 2011). To date, methanogens, such as Methanobrevibacter ruminantium, Methanobrevibacter smithii, Methanobrecibacter millerae, Methanobrevibacter olleyae, Methanobacterium formicicum, Methanobacterium bryantii, Methanosarcina barkeri, Methanosarcina mazai and Methanomicrobium mobile have been isolated by culture methods (Janssen and Kirs, 2008; Sirohi et al., 2010; Kumar et al., 2012).

The above-mentioned isolated species have been proven to utilize limited substrates to produce $\mathrm{CH}_{4}$ (Table 1). However, application of molecular technologies has further revealed that there is considerable genetic diversity in methanogens in the rumen. Methanosphaera stadtmanae, Methanobrevibacter thaueri, Methanobrevi- 
Table 1 - The genera and species of methanogens and methanogenesis substrates in ruminants.

\begin{tabular}{|c|c|c|c|c|}
\hline Animal & Genera & Representative species & Methanogenesis substrates & Reference \\
\hline $\begin{array}{l}\text { Cattle; } \\
\text { ovine }\end{array}$ & Methanobrevibacter & $\begin{array}{l}\text { M.ruminantium; } \\
\text { M.smithii }\end{array}$ & $\begin{array}{l}\mathrm{CO}_{2} / \mathrm{H}_{2} ; \\
\text { formate }\end{array}$ & $\begin{array}{l}\text { (Zhou et al., 2010); } \\
\text { (Liu and Whitman, 2008); } \\
\text { (Kumar et al., 2012) }\end{array}$ \\
\hline Cattle & Methanosphaera & M.stadtmanae & $\begin{array}{l}\mathrm{CO}_{2} / \mathrm{H}_{2} ; \\
\text { methanol }\end{array}$ & $\begin{array}{l}\text { (Zhou et al., 2010); } \\
\text { (Liu and Whitman, 2008) }\end{array}$ \\
\hline Cattle & Methanomicrobium & M.mobile & $\begin{array}{l}\mathrm{CO}_{2} / \mathrm{H}_{2} \\
\text { formate }\end{array}$ & $\begin{array}{l}\text { (Tymensen and McAllister, 2012); } \\
\text { (Liu and Whitman, 2008); } \\
\text { (Sirohi et al., 2010) }\end{array}$ \\
\hline $\begin{array}{l}\text { Cattle; } \\
\text { ovine }\end{array}$ & Methanobacterium & $\begin{array}{l}\text { M.formicicum; } \\
\text { M.bryantii }\end{array}$ & $\begin{array}{l}\mathrm{CO}_{2} / \mathrm{H}_{2} ; \\
\text { formate }\end{array}$ & $\begin{array}{l}\text { (Tymensen and McAllister, 2012); } \\
\text { (Liu and Whitman, 2008); } \\
\text { (Sirohi et al., 2010) }\end{array}$ \\
\hline $\begin{array}{l}\text { Cattle; } \\
\text { goat; } \\
\text { ovine }\end{array}$ & Methanosarcina & $\begin{array}{l}\text { M.barkeri; } \\
\text { M.mazai }\end{array}$ & $\begin{array}{l}\mathrm{CO}_{2} / \mathrm{H}_{2} ; \\
\text { methanol; } \\
\text { acetate }\end{array}$ & $\begin{array}{l}\text { (Denman et al., 2007); } \\
\text { (Liu and Whitman, 2008); } \\
\text { (Sirohi et al., 2010) }\end{array}$ \\
\hline
\end{tabular}

bacter gottschalkii and others have also been identified by the 16S rRNA PCR (Pei et al., 2010; Franzolin et al., 2012). In general, the majority of rumen methanogens detected can be mainly classified into three genera by the analysis of pooled data from several surveys; these are Methanobrevibacter, Methanomicrobium and rumen uncultured cluster C (Tymensen and McAllister, 2012). Of these, Methanobrevibacter accounts for nearly two-thirds (62\%) of rumen methanogens, Methanomicrobium and rumen uncultured cluster $\mathrm{C}$ are roughly equal and account for $15 \%$ and $16 \%$, respectively (Janssen and Kirs, 2008; St-Pierre and Wright, 2013). Nonetheless, the proportion of these groups is reported to differ greatly (Morgavi et al., 2010; St-Pierre and Wright, 2013); these differences may be due to methodological differences or result from effects of animal species and/or diets. The remaining genera of methanogens should also include Methanosphaera, Methanobacterium and Methanosarcina. In our opinion, the fast development of molecular technologies allows for identification, diversity and colonization of more specific and functional methanogens in the rumen.

\section{Pathways of methanogenesis}

In the rumen, methanogens produce $\mathrm{CH}_{4}$ from a limited amount of substrates, namely $\mathrm{H}_{2}+\mathrm{CO}_{2}$, formate, methanol and acetate (Oppermann et al., 1961; Hungate et al., 1970; Neumann et al., 1999; Rea et al., 2007). The $\mathrm{H}_{2}+\mathrm{CO}_{2}$, formate and acetate are derived from carbohydrate fermentation, whereas methanol comes from pectin fermentation. As of today, the pathways of methanogenesis from all above-mentioned precursors have yet to be fully defined in the rumen. As rumen methanogens are difficult to culture, it is useful to gain a better understanding of their metabolism and physiology and to define the pathways of $\mathrm{CH}_{4}$ production in the rumen with the help of genome sequencing technology. Through the application of such technology, M. ruminantium and Methanobrevibacter. AbM4, two prominent methanogens found in the rumen and abomasum respectively, have been confirmed to contain two complete methanogenic pathways for reduction of
$\mathrm{CO}_{2}$ and oxidation of formate to $\mathrm{CH}_{4}$ (Leahy et al., 2010; Leahy et al., 2013). In the light of species or genera of methanogens plus the precursors found in the rumen, other potential pathways (i.e., either acetate or methanol metabolism) might be proposed, even though they are not yet supported by direct experimental data in ruminants.

\section{Pathway of $\mathrm{CO}_{2}$ reduction}

The combination of $\mathrm{H}_{2}+\mathrm{CO}_{2}$ is the most common substrate of methanogens for methanogenesis, and the detailed pathway for the formation of $\mathrm{CH}_{4}$ has been shown previously (Liu and Whitman, 2008). In this pathway, $\mathrm{CO}_{2}$ is reduced successively to $\mathrm{CH}_{4}$ by $\mathrm{H}_{2}$ as the primary electron donor through formyl, methenyl, methylene and methyl intermediates. The reduction of the carbon moiety involves several steps catalyzed by a number of unique cofactors and enzymes (Figure 1).

\section{$\mathrm{CO}_{2}$ reduction to formyl-MFR}

The step of $\mathrm{CO}_{2}$ reduction to formyl-MFR consists of two processes, the binding of $\mathrm{CO}_{2}$ with methanofuran (MFR) as well as its $\mathrm{H}_{2}$-dependent reduction to formylMFR. During the process, ferredoxin has the ability to directly accept an electron to form a reduced state. The MFR, as the $\mathrm{C}_{1}$ carrier, is composed of a $\mathrm{C}_{4}$-substituted furfurylamine ring (Figure 2) and is the only cofactor known to contain a furan moiety. It is present in all known methanogens at the level of $0.5-2.5 \mathrm{mg} \mathrm{kg}-1$ of cell dry weight (Sirohi et al., 2010). The formation of formyl-MFR is catalyzed by formylmethanofuran dehydrogenase (a molybdenum enzyme) which has five distinct subunits when derived from $M$. barkeri. It contains molybdopterin guanine dinucleotide, 30 non-heme iron and 30 acid-labile sulfide molecules.

The genes encoding the five subunits form a transcription unit (fmdEFACDB) and are co-transcribed with an additional gene, $\mathrm{fmdF}$, encoding a polyferredoxin that possibly contains eight [4Fe-4S] clusters (Vorholt et al., 1996). The sequence, deduced from the subunit FmdB, includes a molybdopterin cofactor and indicates FmdB 


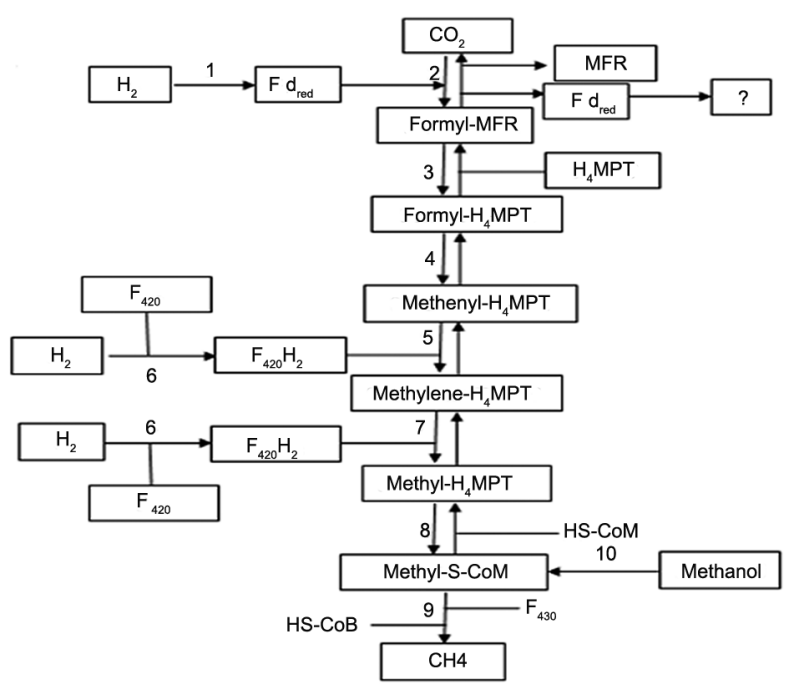

Figure 1 - Pathway of methanogenesis from $\mathrm{H}_{2}+\mathrm{CO}_{2}$ and methanol. $\mathrm{F}_{420} \mathrm{H}_{2}$, reduced form of coenzyme $\mathrm{F}_{420} ; \mathrm{Fd}_{\text {red }}$, reduced form of ferredoxin; MFR, methanofuran; $\mathrm{H}_{4} \mathrm{MPT}$, tetrahydromethanopterin; HS-CoM, coenzyme M; HS-CoB, coenzyme B. Enzymes: 1. Ech hydrogenase; 2. formylmethanofuran dehydrogenase; 3. formyl-MFR: $\mathrm{H}_{4}$ MPT formyltransferase; 4. methenyl- $\mathrm{H}_{4}$ MPT cyclohydrolase; 5. methylene- $\mathrm{H}_{4} \mathrm{MPT}$ dehydrogenase; 6. $\mathrm{F}_{420}$ reducing hydrogenase; 7. methylene- $\mathrm{H}_{4} \mathrm{MPT}$ redutase; 8 . methyl$\mathrm{H}_{4} \mathrm{MPT}$ :HS-CoM methyltransferase; 9. methyl-CoM reductase; 10. methanol:coenzyme methyltransferase.

is the catalytic subunit. In addition, FmdB has the potential ability to bind one [4Fe-4S] cluster. $M$. thermoautotrophicum is shown to include two forms of formylmethanofuran dehydrogenases, one a molybdenum enzyme and the other a tungsten enzyme. The former consists of three distinct subunits (FmdABC) and encodes fm$\mathrm{dECB}$ operon that is only transcribed in the presence of molybdenum, while the latter consists of four different subunits (FwdABCD). The genes of FwdABCD are co-transcribed with three other genes (fwdEFG) to form the fwdEFGDACB operon that is transcribed in the presence of either molybdenum or tungsten. In the fwdEFGDACB, the fwdE and fwdG embody two [4Fe-4S] clusters, whereas the fwdF possesses eight [4Fe-4S] clusters (Hochheimer et al., 1995). The FwdB harboring the active site between FmdABC and FwdABCD has only 47 $\%$ identical amino acid homology and demonstrates that the two dehydrogenases are very different.

\section{Transfer of the formyl group from formyl-MFR to formyl- $\mathrm{H}_{4} \mathrm{MPT}$}

During the transfer processes of formyl-MFR to formyl- $\mathrm{H}_{4} \mathrm{MPT}$, both a coenzyme and an enzyme are involved. The coenzyme $\mathrm{H}_{4} \mathrm{MPT}$, as a $\mathrm{C}_{1}$ carrier, has an electron-donating methylene group in conjugation to $\mathrm{N}^{10}$ via the aromatic ring (Figure 2). The formyl-transferase (Ftr), which has the ability to transfer a formyl group<smiles>[NH3+]c1cc(Oc2ccc(CCNOCCC(NC(=O)CC(NC(=O)CC(C(=O)[O-])C(=O)[O-])C(=O)[O-])C(=O)[O-])cc2)co1</smiles>

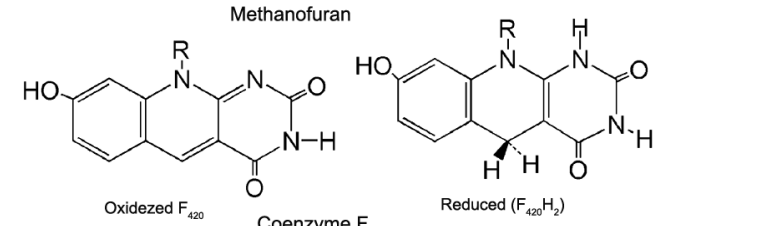

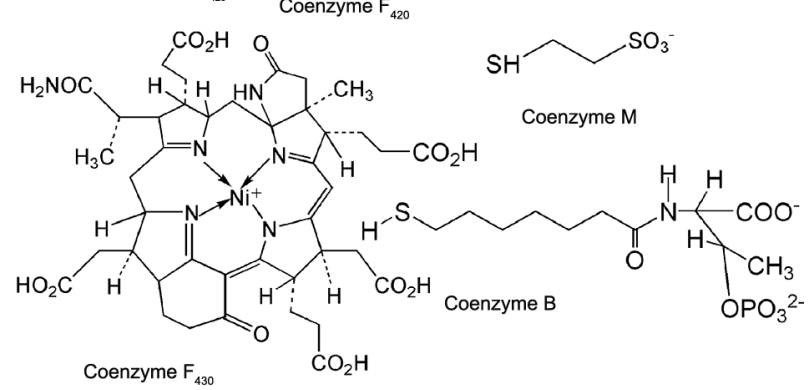

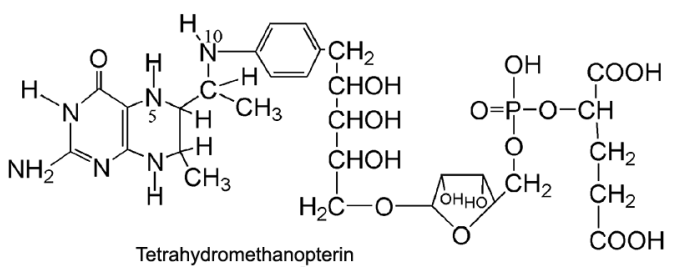

Figure 2 - Structure of methanofuran, coenzyme B, coenzyme M, coenzyme $F_{420}$, coenzyme $F_{430}$ and tetrahydromethanopterin. Adapted from Ferry (1999).

being dependent on the salt concentration, consists of a subunit with a molecular mass of approximately $32 \mathrm{kDa}$ but without the prosthetic group, and exists in a monomer/dimer/tetramer association equilibrium. Of these, the tetramers are thermostable, but the monomers and dimers are the active forms (Mamat et al., 2002). The ftr gene directing the synthesis of functional formyl-transferase in E.coli does not produce an operon and is monocistronic. The amino acid sequences of formyl-transferases from $M$. barkeri and $M$. thermoautotrophicum are $64 \%$ identical. The ftr genes from $M$. barkeri and $M$. thermoautotrophicum encode proteins with isoelectric points of 4.9 and 4.5 , respectively, and their guanine + cytosine $(\mathrm{G}+\mathrm{C})$ contents are $42 \mathrm{~mol} \%$ and $48 \mathrm{~mol} \mathrm{\%}$, respectively (Kunow et al., 1996). Two ftr genes are found in the genomic sequence of $M$. thermoautotrophicum, but only one of them is essential.

\section{Formation of methenyl- $\mathrm{H}_{4} \mathrm{MPT}$}

The process from formyl- $\mathrm{H}_{4}$ MPT to methenyl$\mathrm{H}_{4}$ MPT is catalyzed by methenyl- $\mathrm{H}_{4}$ MPT cyclohydrolase (Mch). The Mch has a molecular mass of approximately $35 \mathrm{kDa}$ and lacks a chromophoric prosthetic group. It is present in a homotrimeric state and is stable under aerobic conditions. The enzymatic process of reversible 
Mch reaction consists of a nucleophilic addition of an activated water molecule followed by a ring-cleavage elimination step (Upadhyay et al., 2012). The mch gene encoding the enzyme from $M$. thermoautotrophicum is apparently transcribed monocistronically. By comparing the mch gene sequence with the deductive mch genes determined from the genomic sequence of $M$. ruminantium, M. smithii, M. barkeri and M. AbM4, the length of the mch gene is approximately 960 bp (Aufhammer et al., 2005; Samuel et al., 2007; Leahy et al., 2010; Leahy et al., 2013), the identity of the genes encoding the four methenyl- $\mathrm{H}_{4}$ MPT cyclohydrolases is $38 \%$ based on multiple sequence comparison. This degree of identity is large when the different genera and phylogenetic development are considered.

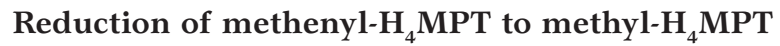

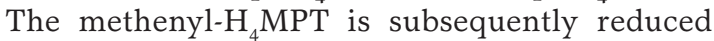
to methylene- $\mathrm{H}_{4}$ MPT and further to methyl- $\mathrm{H}_{4}$ MPT. In both reactions, $\mathrm{F}_{420}$, a deazaflavine derivative, acts as a coenzyme for hydride transfer, and serves as the reductant (Figure 2) (Hendrickson and Leigh, 2008). It has blue green fluorescence in the oxidized state, but not in the reduced state. The $\mathrm{F}_{420}$ in all methanogens usually ranges from 1.2 to $65 \mathrm{mg} \mathrm{kg} \mathrm{mg}^{-1}$ of dry cell weight. During the process of methanogenesis, coenzyme $\mathrm{F}_{420}$ is reduced and catalyzed to $\mathrm{F}_{420} \mathrm{H}_{2}$ (reduced form of coenzyme $\mathrm{F}_{420}$ ) by $\mathrm{H}_{2}$ and $\mathrm{F}_{420}$-reducing hydrogenase, respectively. An alternative pathway is where $\mathrm{F}_{420}$-dependent methylene- $\mathrm{H}_{4} \mathrm{MPT}$ dehydrogenase (Mtd) and $\mathrm{H}_{2}$-forming methylene- $\mathrm{H}_{4} \mathrm{MPT}$ dehydrogenase (Mth) reduce $\mathrm{F}_{420}$ with $\mathrm{H}_{2}$ to form $\mathrm{F}_{420} \mathrm{H}_{2}$, this is called the Mtd-Mth cycle. The hydrogenase consists of three different subunits and contains flavin adenine dinucleotide, nickel, iron, acid-labile sulfide, but not selenium (Vogt et al., 2008). The process from methenyl-H MPT to methylene- $\mathrm{H}_{4}$ MPT is catalyzed by the methylene$\mathrm{H}_{4} \mathrm{MPT}$ dehydrogenase system which consists of Mtd and Mth. The former catalyzes the reversible reduction of methenyl- $\mathrm{H}_{4} \mathrm{MPT}$ and $\mathrm{F}_{420} \mathrm{H}_{2}$ to methylene- $\mathrm{H}_{4} \mathrm{MPT}$ whereas the latter catalyzes the reversible reduction of methenyl- $\mathrm{H}_{4} \mathrm{MPT}$ and molecular hydrogen to methylene- $\mathrm{H}_{4}$ MPT. The Mtd consists of subunits each with an approximate molecular mass of $32 \mathrm{kDa}$ and exists as either a hexamer or an ancotamer lacking of a chromophoric prosthetic group.

The stability of Mtd is relatively long under aerobic conditions $\left(24 \mathrm{~h}, 4{ }^{\circ} \mathrm{C}\right)$, but this declines markedly in the presence of Mth in a strictly anaerobic environment. Consequently, Mtd is usually hard to detect under anaerobic conditions. Because of the strictly anaerobic environment in the rumen, the Mth can directly catalyze the reduction of methenyl- $\mathrm{H}_{4} \mathrm{MPT}$ and molecular hydrogen to methylene- $\mathrm{H}_{4}$ MPT. That is to say, only Mth is involved in the conversion of methenyl- $\mathrm{H}_{4} \mathrm{MPT}$ to methylene- $\mathrm{H}_{4}$ MPT in the rumen, hydrogen taking part in this process as a molecular form rather than as $\mathrm{F}_{420} \mathrm{H}_{2}$. The catalytic mechanism is a ternary complex type similar to the direct hydride transfer to oxidized $\mathrm{F}_{420}$ or from reduced $\mathrm{F}_{420}$. The sequences of mtd genes encoding Mtd have been not only reported in $M$. thermoautotrophicum and $M$. barkeri but also determined from the genomic sequence of $M$. ruminantium, $M$. smithii, Methanosarcina mazei and M. AbM4 (Mukhopadhyay et al., 1995; Deppenmeier et al., 2002; Aufhammer et al., 2005; Leahy et al., 2010; Leahy et al., 2013).

The sequence identity of these various mtd genes is at least $51 \%$, determined by pairwise sequence alignment, which is high for different genera. The sequence analysis of the mtd gene of $M$. thermoautotrophicum indicates that the coenzyme $\mathrm{F}_{420}$ is situated at the N-terminus. The Mth, a novel type of hydrogenase, lacks iron-sulfur clusters, nickel, and flavins, but does contain an iron-guanylypyridinol cofactor (FeGP) as the prosthetic group, and is composed of one type of subunit with a molecular mass of approximately 43 $\mathrm{kDa}$, and is highly $\mathrm{O}_{2}$-sensitive in dimeric form (Shima and Ermler, 2011). The catalytic mechanism of Mth is that a hydride from $\mathrm{H}_{2}$ is transferred to the pro- $\mathrm{R}$ site of the C-14a methenyl group of methenyl- $\mathrm{H}_{4} \mathrm{MPT}$, which

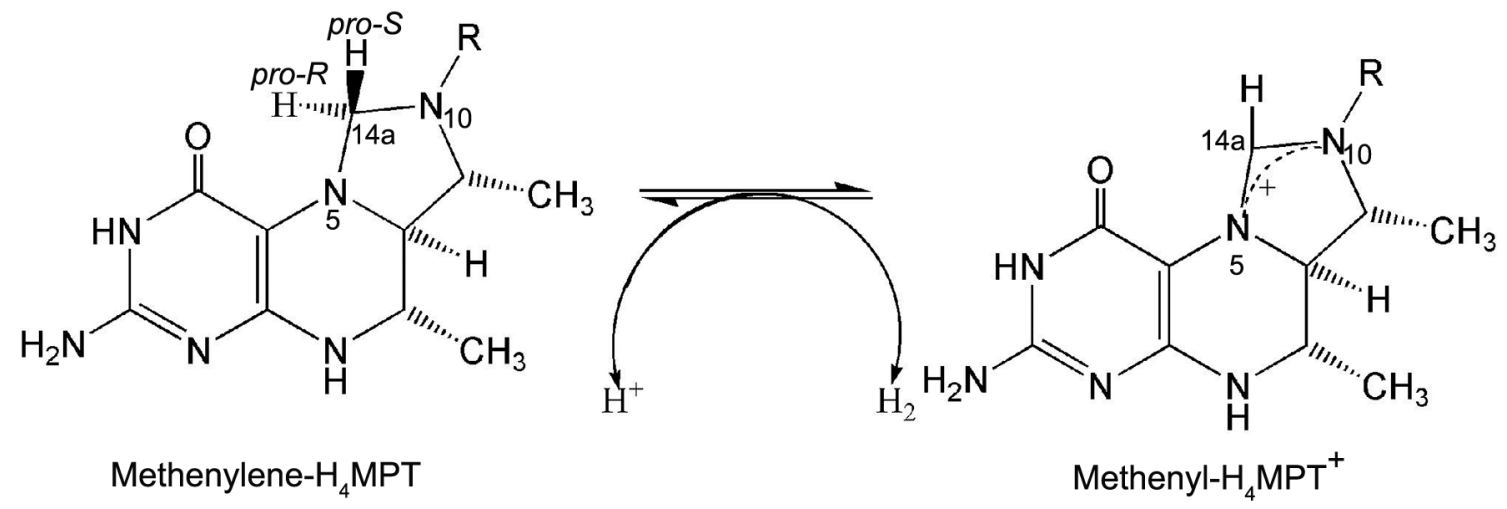

Figure 3 - Reaction catalyzed by the $\mathrm{H}_{2}$-forming methylene- $\mathrm{H}_{4}$ MPT dehydrogenase. Adapted from Ferry (1999). 
leads to changes in hydrogen at the site of the C-14a methylene group of methylene- $\mathrm{H}_{4} \mathrm{MPT}$ (Figure 3 ). The gene encoding Mth from $M$. thermolithotrophicus has been cloned and sequenced. Its genomic sequence is 1059 bp long with ATG and TAA as initiation and termination codons, and includes $39 \mathrm{~mol} \mathrm{\%} \mathrm{G+C} \mathrm{content}$ (Hartmann et al., 1996).

The methylene- $\mathrm{H}_{4}$ MPT reductase catalyzes the re-

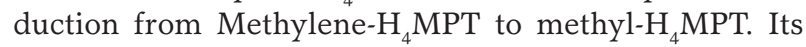
TIM barrel structure contains a nonprolyl cis-peptide bond, but the binding sites of the substrates remain elusive, therefore only its crystal structure in a complex with $\mathrm{F}_{420}$ has been reported (Aufhammer et al., 2005). As a tetramer, it is composed of one type of subunit, each with a molecular mass of approximately $37 \mathrm{kDa}$ with the absence of a chromophoric prosthetic group, such as flavins or iron-sulfur complexes. The gene encoding this reductase from $M$. thermoautotrophicum is 963-966 bp in length with ATG as start codon and TAA as end codon, and encodes a protein consisting of 321 amino acids with a molecular mass of $33.5 \mathrm{kDa}$ and an approximate isoeletric point of 4.5. The transcript of this gene is monocistronic (Nolling et al., 1995).

\section{Reduction of Methyl-H MPT to Methyl-S-CoM}

The coenzyme $\mathrm{M}$ (HS-CoM) and methyl$\mathrm{H}_{4}$ MPT:HS-CoM methyltransferase involve the reductive process of Methyl-H MPT to Methyl-S-CoM. The HS-CoM, as a methyl group carrier, takes part in the crucial step of $\mathrm{CH}_{4}$ formation through accepting the methyl group from methylcobalamin to form Methyl-S-CoM and is the smallest known organic cofactor. The structure of HS-CoM is 2, 2 - dithiodiethanesulfonic acid (Figure 2), and sulfopyruvate decarboxylase plays an important role in its biosynthesis (Sarmiento et al., 2013). In the rumen, some methanogenic archaea, such as $M$. ruminantium, cannot synthesize HS-COM, whereas they can satisfy the growth requirement for the coenzyme by the supply of other methanogens having the ability to produce HSCOM (Krishnakumar et al., 2008).

The methyl- $\mathrm{H}_{4}$ MPT:HS-CoM methyltransferase consisting of eight different subunits (MtrABCDEFGH) and containing 5-hydroxybenzimidazolyl cobamide as a prosthetic group is an integral membrane-bound enzyme complex, which catalyzes the methyl transfer through the generation of a sodium ion gradient across the membrane (Gottschalk and Thauer, 2001). The methyl transfer occurs in two steps; a methyl group is first transferred from Methyl- $\mathrm{H}_{4} \mathrm{MPT}$ to an enzyme-bound cobamide prosthetic group to form methylated cobamide and subsequently HS-CoM. Its transfer depends on the sodium ion gradient in the second step. Both cloning and sequencing of the corresponding genes reveal that the eight $\mathrm{mtr}$ genes form an operon ( $\mathrm{mtrEDCBAFGH}$ ). The operon is located between the methyl-S-CoM reductase I operon ( $\mathrm{mcr}$ ) and a downstream open reading frame predicted to encode a $\mathrm{Na}^{+} / \mathrm{Ca}^{+}, \mathrm{K}^{+}$exchanger (Harms et al., 1995), while the proposed function of the latter is consistent with the methyltransferase in the generation of a sodium gradient. The deduced sequences of MtrB, MtrC, MtrD, and MtrE suggest that they are extremely hydrophobic membrane proteins (Stupperich et al., 1993). On the contrary, MtrA containing corrinoid is thought to have a hydrophobic helical conformation and is only partially integrated into the cytoplasmic face of the cell membrane, based on the deduced sequence (Sauer and Thauer, 1998).

\section{Reduction of methyl-S-CoM to $\mathrm{CH}_{4}$}

The Methyl-CoM reductase catalyzes the reduction process from methyl-S-CoM to $\mathrm{CH}_{4}$, in which coenzyme $\mathrm{B}$ acts as the electron donor and coenzyme $\mathrm{F}_{430}$ as the prosthetic group (Figure 2). Coenzyme B is a colorless cofactor that contains a thiol group and an L-threonine phosphate group which can be specifically recognized by Methyl-CoM reductase. The thiol group displaces $\mathrm{CH}_{4}$ from $\mathrm{M}$ of methyl-CoM and L-threonine phosphate group binds to basic amino acids in Methyl-CoM reductase (Mcr). The Methyl-CoM reductase is a membraneassociated enzyme that contains two genetically distinct isozymes (Mcr I, Mcr II), both are composed of three different subunits (McrABG), whereas the Mcr G subunit from Mcr I is $5 \mathrm{kDa}$ smaller than that from Mcr II (Aldrich et al., 1987). The relative amounts of Mcr I, MCR II present in the cells are changed by concentrations of $\mathrm{H}_{2}$ and $\mathrm{CO}_{2}$ in the culture vessels. In general, Mcr I easily adapts to the environment of low $\mathrm{H}_{2}$ concentration while Mcr II can exist in an environment of high $\mathrm{H}_{2}$ concentration. In the genomic sequences of $M$. ruminants and $M$. AbM4, only Mcr I has been found to date.

Mcr I plays an important role sensitive to supplied $\mathrm{H}_{2}$ in the pathway of $\mathrm{CO}_{2}$ reduction for methanogens (i.e. Ruminococcus albus) (Ntaikou et al., 2008; Leahy et al., 2010; Leahy et al., 2013). At present, the gene encoding McrA has often been used for the assessment of methanogen diversity in the rumen because $\mathrm{Mcr}$ is specific to methanogens (St-Pierre and Wright, 2013). The genes encoding the Mcr enzyme form an operon (mcrBDCGA) which contains two additional genes with unknown functions. In the gene sequence, there are five open reading frames, of which the largest is located at the $3^{\prime}$ end and the second largest at the 5 ' end while the others are situated between these two open reading frames. The known genes ( $\mathrm{mcr} A, \mathrm{mcrB}, \mathrm{mcrG}$ ) have a strong preference for the codon with a $\mathrm{C}$ in the wobble position (Bokranz et al., 1988).

The reactions discussed above are the currently known process of reduction of $\mathrm{CO}_{2}+\mathrm{H}_{2}$ to $\mathrm{CH}_{4}$. In simple terms $\mathrm{CO}_{2}$ is bound to specific carriers and sequentially produces $\mathrm{CH}_{4}$ by reduction with $\mathrm{H}_{2}$ which serves as an electron donor through enzyme catalysis. Although the mechanism of $\mathrm{CO}_{2}$ reduction pathway to $\mathrm{CH}_{4}$ is well defined, its contribution to total enteric $\mathrm{CH}_{4}$ production at different growth and physiological stages and the impact of dietary intervention factors would become the hot spots in ruminants. 


\section{Pathway of formate oxidation}

Formate utilization starts with oxidation to $\mathrm{CO}_{2}$ and subsequently enters the pathway of $\mathrm{CO}_{2}$ reduction. Formate dehydrogenase $(\mathrm{Fdh})$ catalyzes the process of formate to $\mathrm{CO}_{2}+\mathrm{H}_{2}$ and the enzyme contains molybdenum, as a part of the molybdopterin cofactor, flavin adenine diuncleotide, zinc, iron, inorganic sulfur and two distinct subunits (FdhA, FdhB) in an $\alpha \beta$ configuration. The genes encoding the two subunits from $M$. formicium overlap by $1 \mathrm{bp}$. In the entire genomic sequence, the content of adenine phosphate + thymine $(\mathrm{A}+\mathrm{T})$ is 59 mol \%, while in the fdhA gene sequence the $\mathrm{A}+\mathrm{T}$ content is $71 \mathrm{~mol} \%$ (Shuber et al., 1986). In the process of gene expression, the fdhA and fdhB genes are cotranscribed and the starting site lies in $4.3 \mathrm{~kb}$ upstream of the fdhA gene (Patel and Ferry, 1988). Recently, the genes for the dehydrogenase from $M$. maripaludis have begun to attract the attention of researchers. The fdh genome contains two important gene clusters (fdh1, fdh2), one of which (fdh1) plays an important role in the transfer process of formate to $\mathrm{CO}_{2}+\mathrm{H}_{2}$ (Lupa et al., 2008) and can encode two subunits and a putative formate transporter while the other (fdh2) encodes only two subunits (Wood et al., 2003).

\section{Pathway of acetate dissimilation}

Acetate is not only an important intermediate in the anaerobic fermentation of carbohydrate but also a key precursor of methanogenesis by methanogens, in which only two methanogenic genera are currently known to be capable of utilizing acetate to produce $\mathrm{CH}_{4}$.
One is Methanosarcina and the other is Methanosaeta (Methanothrix). The distinction between them is that Methanosarcina has the ability to utilize acetate, $\mathrm{H}_{2}+$ $\mathrm{CO}_{2}$ and methanol, whereas Methanosaeta is capable of utilizing acetate only. Furthermore, the two genera have different affinities. Methanosaeta mainly grows in an environment in which the acetate concentration is below $1 \mathrm{mM}$, but Methanosarcina prefer higher acetate concentrations. Thus, the pathway of acetate dissimilation can be further divided into two branches via Methanosarcina and Methanosaeta. Additionally, the physiological range of acetate concentration is from $15 \mathrm{mM}$ to $55 \mathrm{mM}$ in the rumen, which should favor the growth of Methanosarcina rather than Methanosaeta. To date, Methanosaeta has not been found in the rumen but might exist in the rumen, which is somewhat surprising due to its wide existence in natural habitats (Smith and Ingram-Smith, 2007) and its optimum growth temperature $\left(35-45^{\circ} \mathrm{C}\right)$, similar to that in the rumen.

\section{Methanogenesis from acetate in Methanosarcina}

The pathway of utilizing acetate to produce $\mathrm{CH}_{4}$ for Methanosarcina is shown in Figure 4. In this pathway, acetate is firstly transformed to acetyl-CoA by acetate kinase (Ack) and phosphotransacetylase (Pta) and is then cleaved to enzyme-bound methyl and carbonyl groups by the $\mathrm{CO}$ dehydrogenase/acetyl-CoA synthase complex (Codh). In this cleavage process the carbonyl group is oxidized to $\mathrm{CO}_{2}$ and electrons are transferred to ferredoxin. Meanwhile, the Codh transfers the methyl group to $\mathrm{H}_{4} \mathrm{MPT}$, yielding methyl- $\mathrm{H}_{4} \mathrm{MPT}$. The methyl-
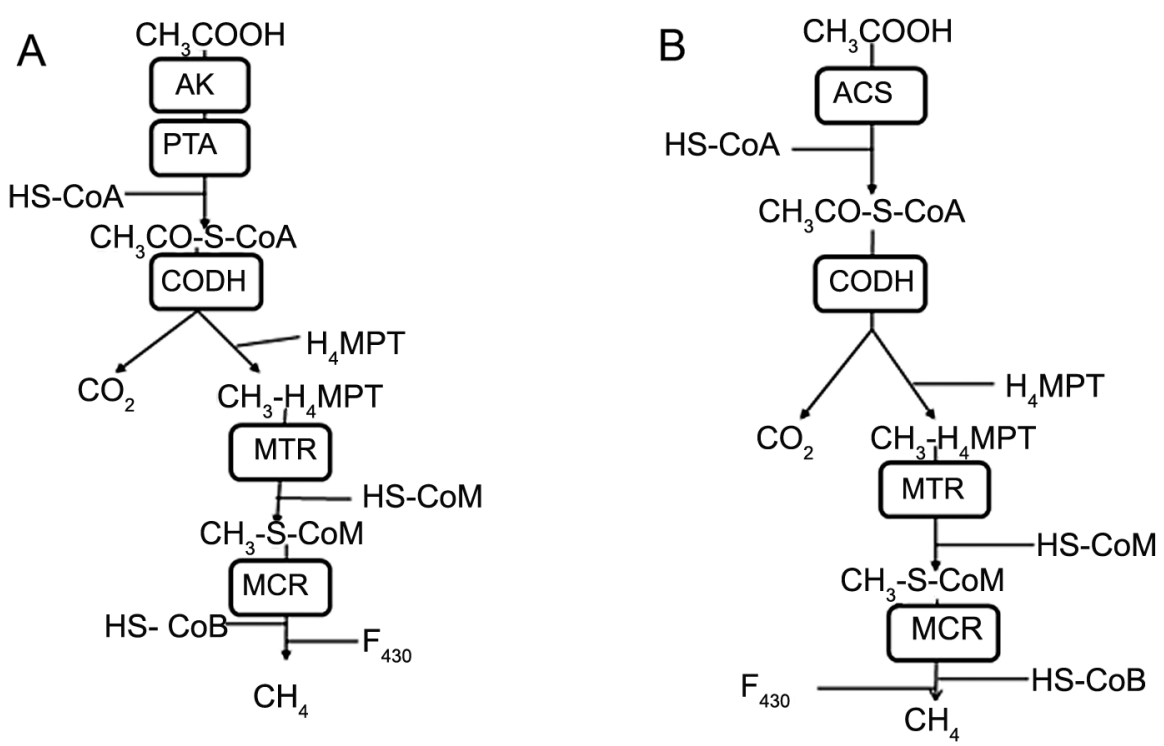

Figure 4 - The two pathways of methanogenesis from acetate. A: Methanosarcina B: Methanosaeta. Abbreviations: AK, acetate kinase; PTA, phosphotransacetylase; ACS, acetyl-CoA synthetase; $\mathrm{CODH}$, carbon monoxide dehydrogenase / acetyl-CoA synthetase complex; MTR, methyltetrahydromethanopterin: CoM methyltransferase; MCR, methyl-CoM methylreductase; HS-CoA, coenzyme A; HS-CoM, coenzyme M; HS-CoB, coenzyme B;H4MPT, tetrahydrosarcinapterin. 
$\mathrm{H}_{4}$ MPT:HS-CoM methyltransferase catalyzes the reaction from methyl- $\mathrm{H}_{4}$ MPT to Methyl-S-CoM which is then reductively to $\mathrm{CH}_{4}$ by methyl-CoM reductase. The process from methyl group to $\mathrm{CH}_{4}$ is a reduction reaction with electrons originating from the oxidation of carboxyl group of the $\mathrm{CH}_{3} \mathrm{CO}-\mathrm{S}-\mathrm{CoA}$ (acetyl-CoA) to $\mathrm{CO}_{2}$. The proton gradient produced by a membrance-bound electron transport chain is used to drive ATP synthesis. The methyltransferase and methyl-CoM reductase have been described in detail earlier as part of the pathway of $\mathrm{CO}_{2}$ reduction and, therefore, only Ack, Pta and Codh are described here.

\section{Acetate kinase and phosphotransacetylase}

In the pathway, acetate kinase catalyzes the synthesis of acetyl phosphate by transfer of the ATP $\gamma$-phosphoryl group to acetate, phosphotransacetylase catalyzes the transfer of the acetyl moiety to CoA to form $\mathrm{CH}_{3} \mathrm{CO}-\mathrm{S}-\mathrm{CoA}$ (acetyl-CoA) and orthophosphate. Acetate kinase contains a hydrophobic pocket for binding the methyl group of acetate and forms the residues $\mathrm{Val}^{93}{ } \mathrm{Phe}^{179}{ }^{17 \mathrm{PrO}^{232}}$ and Leu ${ }^{122}$ (Figure 5) (Ingram-Smith et al., 2005). The catalytic mechanism of acetate kinase is a direct in-line transfer (Figure 6) (Ferry, 2011), and the catalytic process can be completed by nucleophilic at-
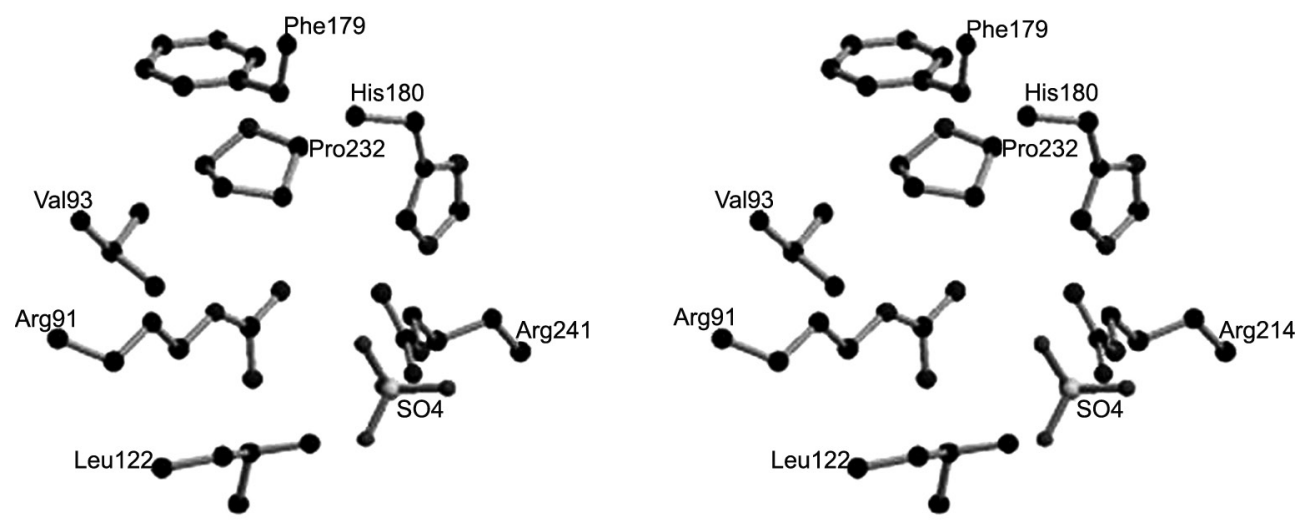

Figure 5 - Stereo view of the proposed acetate binding site in the acetate kinase from M. thermophila. Adapted from Ingram-Smith (2005).

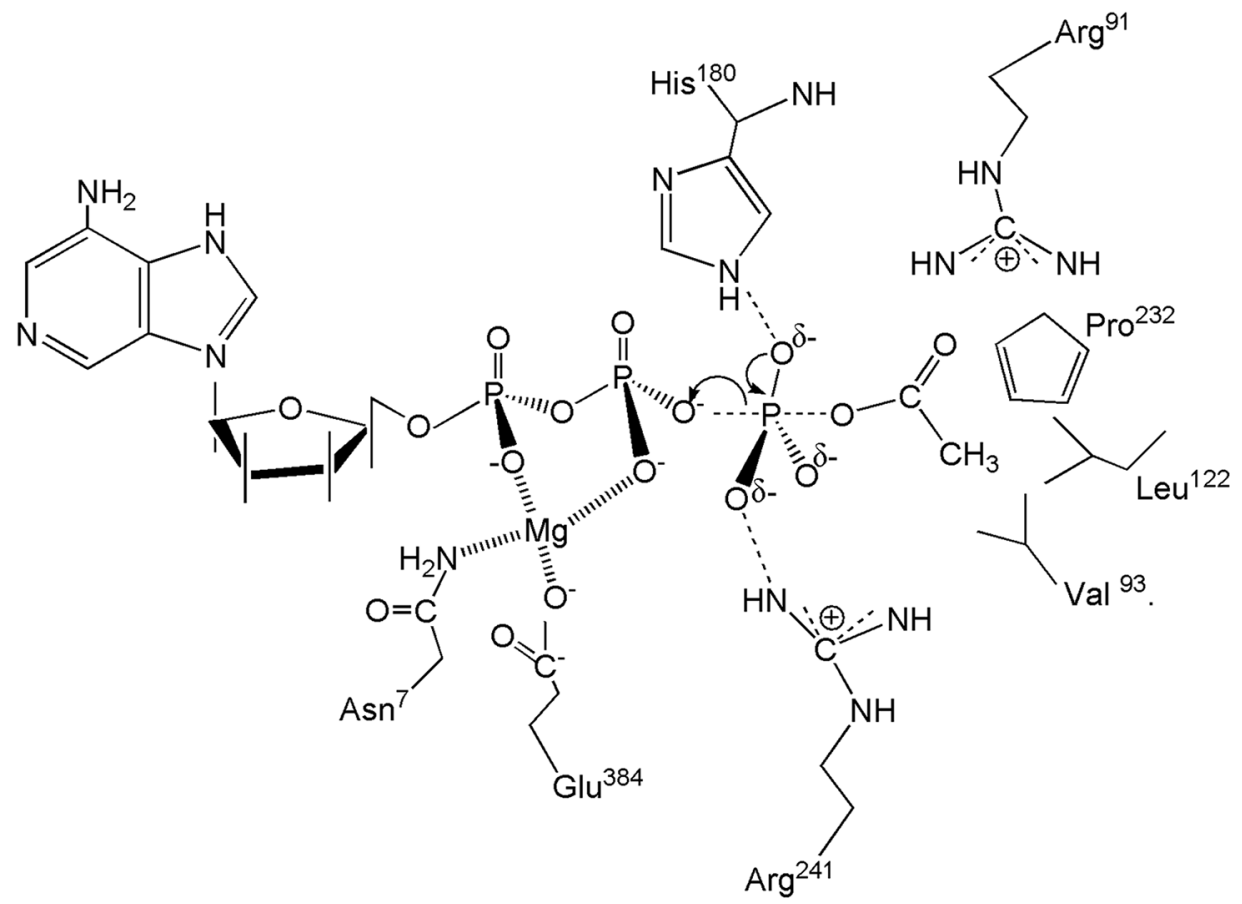

Figure 6 - Postulated mechanism of acetate kinase from M.thermophila. The transition and acetyl phosphate synthesis are in the same direction. The process is completed by nucleophilic attack of the carboxyl group of acetate on the g-phosphate of ATP. The transition state is very stable due to coordination of the equatorial oxygen atoms and interactions with $\mathrm{His}^{180}$ and $\mathrm{Arg}^{241}$. 
tack of the carboxyl group of acetate on the $\gamma$-phosphate of ATP.

The phosphotransacetylase with a molecular weight of $71 \mathrm{kDa}$ is a dimer, classified as an $\mathrm{AB}$ dimer and a CD dimer in the crystalline and soluble state respectively. Each of four monomers is composed of two domains, named I and II. The two domains are approximately the same size and have an $\alpha \beta$ structure. Domain I is made up of a five-stranded $\beta$ sheet $(\beta 3, \beta 2$, $\beta 1, \beta 4$ and $\beta 11$ ) which is surrounded by four A helices and a small helix on each side. However, domain II includes a six-stranded $\beta$ sheet $(\beta 10, \beta 5, \beta 6, \beta 9, \beta 7$ and $\beta 8$ ) surrounded on one side by three helices and on the opposite side by two helices (Iyer et al., 2004). The genes (pta and ack) encoding Pta and Ack from $M$. thermophila are arranged in an operon with pta upstream of ack, similar to the situation with $M$. mazei (Tonouchi et al., 2002). The pta and ack genes encode polypeptides with a molecular weight of $35 \mathrm{kDa}$ and $44 \mathrm{kDa}$ respectively and are co-transcribed as a $2.4 \mathrm{~kb}$ polycistronic message. The molecular mass of the polypeptide encoded by the ack gene is identical with that from M. mazei (44.5 kDa) (Tonouchi et al., 2002). The transcriptional starting site of the genes locates $27 \mathrm{bp}$ upstream from the translational start of the pta gene and $24 \mathrm{bp}$ downstream from a consensus archaeal boxA promoter sequence. The regulation of Pta and Ack synthesis occurs, at least in part, at the mRNA level based on northern blot analyses. At the same time, southern blot analysis indicates that only one copy of each gene is present per chromosome.

\section{Carbon monoxide dehydrogenase/acetyl-CoA syn- thase complex (Codh)}

The Codh is made of five different subunits /Cod$\mathrm{hABCDE}$ ) and plays a major role in the pathway. Through detergent treatment, the enzyme complex has been divided into two components, one of which is a nickel/ iron-sulfur enzyme including CodhA, CodhB and CodhE subunits (Murakami and Ragsdale, 2000), the other is a corrinoid/iron-sulfur enzyme consisting of CodhC and CodhD. The former mainly catalyzes $\mathrm{CO}$ oxidation and decomposes acetyl-CoA into the methyl, carbonyl and CoA moieties. The latter is involved in the transmethylation reaction. Three metal clusters $(\mathrm{A}, \mathrm{B}$ and $\mathrm{C})$ are identified from the $\alpha \beta \varepsilon$ component by electron paramagnetic resonance spectroscopy. Cluster $\mathrm{A}$, a novel Ni-X$\left[\mathrm{Fe}_{4}-\mathrm{S}_{4}\right]$ cluster in which $\mathrm{X}$ is an unknown bridging atom, functions as a synthesizer or splitter of the C-C and C-S bonds of acetyl-CoA. Cluster $\mathrm{C}$, possessing $\mathrm{CO}$ dehydrogenase activity, is also a bimetallic $\mathrm{Ni}-\mathrm{X}-\left[\mathrm{Fe}_{4}-\mathrm{S}_{4}\right]$ cluster. Cluster $\mathrm{B}$, a conventional $\mathrm{Fe}_{4} \mathrm{~S}_{4}$ center thought to shuttle electrons, has the same function as cluster $\mathrm{A}$.

The codh genes encoding the five subunits of the Codh complex from $M$. thermophila have been cloned, sequenced and expressed. The sequence analysis of the codh genes indicates that the proteins encoding these five subunits have different molecular masses and iso- electric points, and further suggests they do not belong to a same kind (Maupin-Furlow and Ferry, 1996). The codh genes and an additional open reading frame with unknown function are co-transcribed based on northern blot analysis. The result suggests the sixth subunit may be required for acetyl-CoA cleavage or maturation of the five subunit complex. The regulation of the Codh complex is at the level of transcription via three mechanisms, one is differential transcription initiation, another is early elongation termination and the last is transcription elongation (Anderson et al., 2009).

\section{Methanogenesis from acetate in Methanosaeta}

The core step of the Methanosaeta pathway (Figure 4) is similar to that of Methanosarcina. The only distinction between these two pathways is the use of different enzymes in the step from acetyl moiety of acetate to CoA forming $\mathrm{CH}_{3} \mathrm{CO}-\mathrm{S}-\mathrm{CoA}$ (acetyl-CoA). The former is catalyzed by acetyl-CoA synthetase (Acs), whereas Ack and Pta are involved in the latter.

\section{Acetyl-CoA synthetase (Acs)}

This enzyme comprises ADP-forming Acetyl-CoA synthetase involved in the formation of acetate and AMP-forming Acetyl-CoA synthetase being operative in the activation of acetate to acetyl-CoA. In the rumen, acetate is constantly produced by bacterial decomposition of cellulose and the acetate concentration is usually high. Hence, activation of acetate to acetyl-CoA by AMP-forming Acetyl-CoA plays an important role in methanogenesis. The AMP-forming Acetyl-CoA from $M$. sothngenii is composed of three different subunits of 18-75 $\mathrm{kDa}$, and sited in the same direction in the gene sequence (Eggen et al., 1991). However, in the genome of $M$. tharmophila, four distinct subunits forming the enzyme are found (Berger et al., 2012). The subunit with a molecular mass of $75 \mathrm{kDa}$ among all the subunits from both methanogens has the potential to synthesize AcetylCoA. According to the deduced sequence of Acetyl-CoA synthetase from both methanogens, the sequence similarity is high, and can reach $80 \%$ identity for the 1990 amino acids.

\section{Pathway of methanol conversion to methane}

This pathway is composed of two separate steps (Figure 1). First, the methanol:coenzyme methyltransferase system catalyzes the methyl group of methanol and coenzyme M to form methyl-S-CoM directly. Second, the reduction of methyl-S-CoM to $\mathrm{CH}_{4}$ is catalyzed by methyl-CoM reductase. The second step is identical to that which previously describes the reduction of $\mathrm{CO}_{2}$ and, therefore, only the methanol:coenzyme methyltransferase system is detailed here.

The methanol:coenzyme methyltransferase system contains two components which catalyze two reactions and lead to an overall transfer of the methyl group of methanol to HS-CoM. In the first reaction, methanol is transformed by a methanol:5-hydroxy- 
benzimidazolycobamide methyltransferase $\left(\mathrm{Mt}_{1}\right)$ into 2-(methylthio)-ethanesulfonate. In the second reaction, 2-(Methylthio)-ethanesulfonate is reductively cleaved into $\mathrm{CH}_{4}$ and 2-mercaptoethanesulfonate by methylcobamide:coenzymeM methyltransferase $\left(\mathrm{Mt}_{2}\right)$. The $\mathrm{Mt}_{1}$ component consists of two subunits (MtaB and $\mathrm{MtaC}$ ). The MtaC harbors corrinoids as prosthetic groups and the MtaB transferring the methyl group of methanol to the corrinoid prosthetic group of MtaC contains a mole of zinc, and its activity is zinc-dependent (Sauer and Thauer, 1997). The $\mathrm{Mt}_{1}$ component binding the methyl group of methanol, when the cobalt atom of its corrinoid prosthetic groups is in the highly reduced state, can be reactivated under the oxidized state. The $\mathrm{Mt}_{2}$ component is composed simply of a subunit MtaA with a molecular mass of $36 \mathrm{kDa}$ but without any prosthetic groups.

The $\mathrm{mtaA}, \mathrm{mtaB}$ and $\mathrm{mtaC}$ genes from $M$. barkeri encoding MtaA, MtaB and MtaC respectively, have been cloned and sequenced (Harms and Thauer, 1996). In the sequence, not only do the genes ( $\mathrm{mtaB}$ and $\mathrm{mtaC}$ ) locate in the same area and form an operon $m t^{2} \mathrm{CB}$, but also the gene $\mathrm{mtaB}$ is situated directly downstream of $\mathrm{mtaC}$, suggesting both subunits have a similar function. The mtaCB operon does not contain the gene mtaA, indicating the mtaA has a function that is different from the other subunit. The same results have been demonstrated by northern blot analysis indicating that the gene mtaA is monocistronically transcribed while the other genes ( $\mathrm{mtaB}$ and $\mathrm{mtaC})$ are co-transcribed.

For three methanogenesis pathways (i.e., formate oxidation, acetate dissimilation and methanol disportionation), information about their mechanisms is relatively limited in the rumen. Therefore, identification of some specific methanogens (i.e., Methanosarcina and Methanosaeta) and their genomic sequences, validation of acetate dissimilation and methanol disportionation in the rumen, and the contribution of each pathway to total enteric $\mathrm{CH}_{4}$ production should be emphasized at different growth and physiological stages and under different dietary conditions in ruminants.

\section{Final Remarks}

The pathways of $\mathrm{CO}_{2}$ reduction and formate oxidation assuredly exist in the rumen, and they involve a process of complex reactions due to the many coenzymes and enzymes involved. The pathways of acetate and methanol metabolism might be present in the rumen dependent on species or genera of methanogens and the presence of precursors which can form $\mathrm{CH}_{4}$. In the future, the existence of unconfirmed pathways (pathways of acetate dissimilation as well as methanol conversion), proportional contribution to enteric $\mathrm{CH}_{4}$ production from each pathway at different physiological or growth stages, and their regulatory processes in ruminants need to be clarified. Meanwhile, more methanogens from the rumen should be isolated, identified and cultured to fur- ther understand their specific functions. The genome sequences or the cloning and sequencing of genes encoding the relevant enzymes for more specific methanogens should be studied to provide new insights into enzyme evolution, regulation of gene expression, mechanisms of catalysis, relationships between host species or diet and population structure of symbiotic methanogens, and to explore more effective technologies of mitigating enteric $\mathrm{CH}_{4}$ emissions.

\section{Acknowledgement}

The authors wish to thank the "Strategic Priority Research Program - Climate Change: Carbon Budget and Relevant Issues" (Grant No. XDA05020700) and Knowledge Innovation Program of CAS (Grant No. KZCX2YW-455) of the Chinese Academy of Sciences, and National Natural Science Foundation of China (Grant No. 31320103917 and No.31001023) for their joint financial support.

\section{References}

Aldrich, H.C.; Beimborn, D.B.; Bokranz, M.; Schonheit, P. 1987. Immunocytochemical localization of methyl-coenzyme $M$ reductase in Methanobacterium thermoautotrophicum. Archives of Microbiology 147: 190-194.

Anderson, K.L.; Apolinario, E.E.; MacAuley, S.R.; Sowers, K.R. 2009. A 5' leader sequence regulates expression of Methanosarcinal CO dehydrogenase/acetyl coenzyme A synthase. Journal of Bacteriology 191: 7123-7128.

Attwood, G.T.; Altermann, E.; Kelly, W.J.; Leahy, S.C.; Zhang, L.; Morrison, M. 2011. Exploring rumen methanogen genomes to identify targets for methane mitigation strategies. Animal Feed Science and Technology 166-167: 65-75.

Aufhammer, S.W.; Warkentin, E.; Ermler, U.; Hagemeier, C.H.; Thauer, R.K.; Shima, S. 2005. Crystal structure of methylenetetrahydromethanopterin reductase (Mer) in complex with coenzyme $\mathrm{F}_{420}$ : Architecture of the $\mathrm{F}_{420} / \mathrm{FMN}$ binding site of enzymes within the nonprolyl cis-peptide containing bacterial luciferase family. Protein Science 14: 18401849.

Beauchemin, K.A.; Kreuzer, M.; O'Mara, F.; McAllister, T.A. 2008. Nutritional management for enteric methane abatement: a review. Australian Journal of Experimental Agriculture 48: 21-27.

Berger, S.; Welte, C.; Deppenmeier, U. 2012. Acetate activation in Methanosaeta thermophila: characterization of the key enzymes pyrophosphatase and acetyl-CoA synthetase. Archaea 2012: 1-10.

Bokranz, M.; Baumner, G.; Allmansberger, R.; Ankelfuchs, D.; Klein, A. 1988. Cloning and characterization of the methyl-coenzyme M reductase genes from Methanobacterium thermoautotrophicum. Journal of Bacteriology 170: 568-577.

Denman, S.E.; Tomkins, N.W.; McSweeney, C.S. 2007. Quantitation and diversity analysis of ruminal methanogenic populations in response to the antimethanogenic compound bromochloromethane. Fems Microbiology Ecology 62: 313-322. 
Deppenmeier, U.; Johann, A.; Hartsch, T.; Merkl, R.; Schmitz, R.A.; Martinez-Arias, R.; Henne, A.; Wiezer, A.; Baumer, S.; Jacobi, C.; Brüggemann, H.; Lienard, T.; Christmann, A.; Bömeke, M.; Steckel, S.; Bhattacharyya, A.; Lykidis, A.; Overbeek, R.; Klenk, H.P.; Gunsalus, R.P.; Fritz, H.J.; Gottschalk, G. 2002. The genome of Methanosarcina mazei: evidence for lateral gene transfer between bacteria and archaea. Journal of Molecular Microbiology and Biotechnology 4: 453-461.

Eggen, R.I.L.; Geerling, A.C.M.; Boshoven, A.B.P.; Devos, W.M. 1991. Cloning, sequence analysis, and functional expression of the acetyl coenzyme-A synthetase gene from Methanothrix soehngenii in escherichia coli. Journal of Bacteriology 173: 63836389.

Ferry, J.G. 1999. Enzymology of one-carbon metabolism in methanogenic pathways. FEMS Microbiology Reviews 23: 1338.

Ferry, J.G. 2011. Acetate kinase and phosphotransacetylase. Methods in Enzymology 494: 219-231.

Franzolin, R.; St-Pierre, B.; Northwood, K.; Wright, A.D.G. 2012. Analysis of rumen methanogen diversity in water buffaloes (bubalus bubalis) under three different diets. Microbial Ecology 64: 131-139.

Gottschalk, G.; Thauer, R.K. 2001. The $\mathrm{Na}^{+}$-translocating methyltransferase complex from methanogenic archaea. Biochimica Et Biophysica Acta 1505: 28-36.

Harms, U.; Thauer, R.K. 1996. Methylcobalamin: coenzyme M methyltransferase isoenzymes MtaA and MtbA from Methanosarcina barkeri: Cloning, sequencing and differential transcription of the encoding genes, and functional overexpression of the mtaA gene in Escherichia coli. European Journal of Biochemistry 235: 653-659.

Harms, U.; Weiss, D.S.; Gartner, P.; Linder, D.; Thauer, R.K. 1995. The energy conserving $\mathrm{N}^{5}$-methyltetrahydromethanopterin: coenzyme-M methyltransferase complex from Methanobacterium thermoautotrophicum is composed of eight different subunits. European Journal of Biochemistry 228: 640-648.

Hartmann, G.C.; Klein, A.R.; Linder, M.; Thauer, R.K. 1996. Purification, properties and primary structure of $\mathrm{H}_{2}$-formingN $\mathrm{N}^{5}$, $\mathrm{N}^{10}$-methylenetetrahydromethanopterin dehydrogenase from Methanococcus thermolithotrophicus. Archives of Microbiology 165: 187-193.

Hendrickson, E.L.; Leigh, J.A. 2008. Roles of coenzyme $\mathrm{F}_{420^{-}}$ reducing hydrogenases and hydrogen- and $\mathrm{F}_{420}$-dependent methylenetetrahydromethailopterin dehydrogenases in reduction of $\mathrm{F}_{420}$ and production of hydrogen during methanogenesis. Journal of Bacteriology 190: 4818-4821.

Hochheimer, A.; Schmitz, R.A.; Thauer, R.K.; Hedderich, R. 1995. The tungsten formylmethanofuran dehydrogenase from Methanobacterium thermoautotrophicum contains sequence motifs characteristic for enzymes containing molybdopterin dinucleotide. European Journal of Biochemistry 234: 910-920.

Hungate, R.E.; Smith, W.; Bauchop, T.; Yu, I.; Rabinowitz, J.C. 1970. Formate as an intermediate in the bovine rumen fermentation. Journal of Bacteriology 102: 389-397.

Ingram-Smith, C.; Gorrell, A.; Lawrence, S.H.; Iyer, P.; Smith, K.; Ferry, J.G. 2005. Characterization of the acetate binding pocket in the Methanosarcina thermophila acetate kinase. Journal of Bacteriology 187: 2386-2394.
Ingram-Smith, C.; Gorrell, A.; Lawrence, S.H.; Iyer, P.; Smith, K.; Ferry, J.G. 2005. Characterization of the acetate binding pocket in the Methanosarcina thermophila acetate kinase. Journal of Bacteriology 187: 2386-2394.

Iyer, P.P.; Lawrence, S.H.; Luther, K.B.; Rajashankar, K.R.; Yennawar, H.P.; Ferry, J.G.; Schindelin, H. 2004. Crystal structure of phosphotransacetylase from the methanogenic archaeon Methanosarcina thermophila. Structure 12: 559-567.

Janssen, P.H.; Kirs, M. 2008. Structure of the archaeal community of the rumen. Applied and Environmental Microbiology 74: 3619-3625.

Krishnakumar, A.M.; Sliwa, D.; Endrizzi, J.A.; Boyd, E.S.; Ensign, S.A.; Peters, J.W. 2008. Getting a handle on the role of coenzyme $\mathrm{M}$ in alkene metabolism. Microbiology and Molecular Biology Reviews 72: 445-456.

Kumar, S.; Dagar, S.S.; Puniya, A.K. 2012. Isolation and characterization of methanogens from rumen of Murrah buffalo. Annals of Microbiology 62: 345-350.

Kunow, J.; Shima, S.; Vorholt, J.A.; Thauer, R.K. 1996. Primary structure and properties of the formyltransferase from the mesophilic Methanosarcina barkeri: Comparison with the enzymes from thermophilic and hyperthermophilic methanogens. Archives of Microbiology 165: 97-105.

Leahy, S.C.; Kelly, W.J.; Altermann, E.; Ronimus, R.S.; Yeoman, C.J.; Pacheco, D.M.; Li, D.; Kong, Z.H.; McTavish, S.; Sang, C.; Lambie, S.C.; Janssen, P.H.; Dey, D.; Attwood, G.T. 2010. The genome sequence of the rumen methanogen Methanobrevibacter ruminantium reveals new possibilities for controlling ruminant methane emissions. PLoS One 5: 1-17.

Leahy, S.C.; Kelly, W.J.; Li, D.; Li, Y.; Altermann, E.; Lambie, S.C.; Cox, F.; Attwood, G.T. 2013. The complete genome sequence of Methanobrevibacter sp. AbM4. Standards in Genomic Sciences 8: 215-227.

Liu, Y.C.; Whitman, W.B. 2008. Metabolic, phylogenetic, and ecological diversity of the methanogenic archaea. Annals of the New York Academy of Sciences 1125: 171-189.

Lupa, B.; Hendrickson, E.L.; Leigh, J.A.; Whitman, W.B. 2008. Formate-dependent $\mathrm{H}_{2}$ production by the mesophilic methanogen Methanococcus maripaludis. Applied and Environmental Microbiology 74: 6584-6590.

Mamat, B.; Roth, A.; Grimm, C.; Ermler, U.; Tziatzios, C.; Schubert, D.; Thauer, R.K.; Shima, S. 2002. Crystal structures and enzymatic properties of three formyltransferases from archaea: environmental adaptation and evolutionary relationship. Protein Science 11: 2168-2178.

Maupin-Furlow, J.A.; Ferry, J.G. 1996. Analysis of the CO dehydrogenase/ acetyl-coenzyme A synthase operon of Methanosarcina thermophila. Journal of Bacteriology 178: 6849-6856.

Morgavi, D.P.; Forano, E.; Martin, C.; Newbold, C.J. 2010. Microbial ecosystem and methanogenesis in ruminants. Animal 4: 1024-1036.

Mukhopadhyay, B.; Purwantini, E.; Pihl, T.D.; Reeve, J.N.; Daniels, L. 1995. Cloning, sequencing, and transcriptional analysis of the coenzyme $\mathrm{F}_{420}$-dependent methylene5,6,7,8-tetrahydromethanopterin dehydrogenase gene from Methanobacterium thermoautotrophicum strain marburg and functional expression in Escherichia coli. Journal of Biological Chemistry 270: 2827-2832. 
Murakami, E.; Ragsdale, S.W. 2000. Evidence for intersubunit communication during acetyl-CoA cleavage by the multienzyme $\mathrm{CO}$ dehydrogenase/acetyl-CoA synthase complex from Methanosarcina thermophila: Evidence that the beta subunit catalyzes C-C and C-S bond cleavage. Journal of Biological Chemistry 275: 4699-4707.

Neumann, L.; Weigand, E.; Most, E. 1999. Effect of methanol on methanogenesis and fermentation in the rumen simulation technique (RUSITEC). Journal of Animal Physiology and Animal Nutrition 82: 142-149.

Nolling, J.; Pihl, T.D.; Reeve, J.N. 1995. Cloning, sequencing, and growth phase-dependent transcription of the coenzyme $\mathrm{F}_{420}$-dependent $\mathrm{N}^{5}, \quad \mathrm{~N}^{10}$-methylenetetrahydromethanopterin reductase-encoding genes from Methanobacterium thermoautotrophicum delta $H$ and methanopyrus kandleri. Journal of Bacteriology 177: 7238-7244.

Ntaikou, I.; Gavala, H.N.; Kornaros, M.; Lyberatos, G. 2008. Hydrogen production from sugars and sweet sorghum biomass using Ruminococcus albus. International Journal of Hydrogen Energy 33: 1153-1163.

Oppermann, R.; Nelson, W.O.; Brown, R.E. 1961. In vivo studies of methanogenesis in bovine rumen: dissimilation of acetate. Journal of General Microbiology 25: 103-111.

Patel, P.S.; Ferry, J.G. 1988. Characterization of the upstream region of the formate dehydrogenase operon of Methanobacterium formicicum. Journal of Bacteriology 170: 3390-3395.

Pei, C.X.; Mao, S.Y.; Cheng, Y.F.; Zhu, W.Y. 2010. Diversity, abundance and novel 16S rRNA gene sequences of methanogens in rumen liquid, solid and epithelium fractions of Jinnan cattle. Animal 4: 20-29.

Rea, S.; Bowman, J.P.; Popovski, S.; Pimm, C.; Wright, A.D.G. 2007. Methanobrevibacter millerae sp nov and Methanobrevibacter olleyae sp nov., methanogens from the ovine and bovine rumen that can utilize formate for growth. International Journal of Systematic and Evolutionary Microbiology 57: 450-456.

Samuel, B.S.; Hansen, E.E.; Manchester, J.K.; Coutinho, P.M.; Henrissat, B.; Fulton, R.; Latreille, P.; Kim, K.; Wilson, R.K.; Gordon, J.I. 2007. Genomic and metabolic adaptations of Methanobrevibacter smithii to the human gut. Proceedings of the National Academy of Sciences of the United States of America 104: 10643-10648.

Sarmiento, F.; Ellison, C.K.; Whitman, W.B. 2013. Genetic confirmation of the role of sulfopyruvate decarboxylase in coenzyme M biosynthesis in Methanococcus maripaludis. Archaea 1-7. DOI: http://dx.doi.org/10.1155/2013/185250

Sauer, K.; Thauer, R.K. 1997. Methanol:coenzyme M methyltransferase from Methanosarcina barkeri: zinc dependence and thermodynamics of the methanol:cob(I)alamin methyltransferase reaction. European Journal of Biochemistry 249: $280-285$.

Sauer, K.; Thauer, R.K. 1998. His(84) rather than His(35) is the active site histidine in the corrinoid protein MtrA of the energy conserving methyltransferase complex from Methanobacterium thermoautotrophicum. Febs Letters 436: 401-402.
Shima, S.; Ermler, U. 2011. Structure and function of [Fe]hydrogenase and its iron-guanylylpyridinol (FeGP) cofactor. European Journal of Inorganic Chemistry 7: 963-972.

Shuber, A.P.; Orr, E.C.; Recny, M.A.; Schendel, P.F.; May, H.D.; Schauer, N.L.; Ferry, J.G. 1986. cloning, expression, and nucleotide sequence of the formate dehydrogenase genes from methanobacterium formicicum. Journal of Biological Chemistry 261: 12942-12947.

Sirohi, S.K.; Pandey, N.; Singh, B.; Puniya, A.K. 2010. Rumen methanogens: a review. Indian Journal of Microbiology 50: 253-262.

Smith, K.S.; Ingram-Smith, C. 2007. Methanosaeta, the forgotten methanogen? Trends In Microbiology 15: 150-155.

St-Pierre, B.; Wright, A.D.G. 2013. Diversity of gut methanogens in herbivorous animals. Animal 7: 49-56.

Stupperich, E.; Juza, A.; Hoppert, M.; Mayer, F. 1993. Cloning, sequencing and immunological characterization of the corrinoidcontaining subunit of the $\mathrm{N}^{5}$-methyltetrahydromethanopterin: coenzyme-M methyltransferase from Methanobacterium thermoautotrophicum. European Journal of Biochemistry 217: 115-121.

Tonouchi, A.; Nishizaki, Y.; Tohyama, H.; Takeda, K. 2002. Cloning of a gene encoding acetate kinase from Methanosarcina mazei 2-P isolated from a Japanese paddy field soil. Current Microbiology 45: 390-393.

Tymensen, L.D.; McAllister, T.A. 2012. Community structure analysis of methanogens associated with rumen protozoa reveals bias in universal archaeal primers. Applied and Environmental Microbiology 78: 4051-4056.

Upadhyay, V.; Demmer, U.; Warkentin, E.; Moll, J.; Shima, S.; Ermler, U. 2012. Structure and catalytic mechanism of $\mathrm{N}^{5}, \quad \mathrm{~N}^{10}$-methenyltetrahydromethanopterin cyclohydrolase. Biochemistry 51: 8435-8443.

Vogt, S.; Lyon, E.J.; Shima, S.; Thauer, R.K. 2008. The exchange activities of $\mathrm{Fe}$ hydrogenase (iron-sulfur-cluster-free hydrogenase) from methanogenic archaea in comparison with the exchange activities of $\mathrm{FeFe}$ and NiFe hydrogenases. Journal of Biological Inorganic Chemistry 13: 97-106.

Vorholt, J.A.; Vaupel, M.; Thauer, R.K. 1996. A polyferredoxin with eight $4 \mathrm{Fe}-4 \mathrm{~S}$ clusters as a subunit of molybdenum formylmethanofuran dehydrogenase from Methanosarcina barkeri. European Journal of Biochemistry 236: 309-317.

Woese, C.R.; Magrum, L.J.; Fox, G.E. 1978. Archaebacteria. Journal of Molecular Evolution 11: 245-251.

Wood, G.E.; Haydock, A.K.; Leigh, J.A. 2003. Function and regulation of the formate dehydrogenase genes of the methanogenic Archaeon Methanococcus maripaludis. Journal of Bacteriology 185: 2548-2554.

Zhou M.; Hernandez-Sanabria E.; Guan L.L. 2010. Characterization of variation in rumen methanogenic communities under different dietary and host feed efficiency conditions, as determined by PCR-denaturing gradient gel electrophoresis analysis. Applied and Environmental Microbiology 76: 37763786. 